\section{IMAGING MECHANISMS IN THE ELECTRON MICROSCOPE}

\section{Fundamentals of Transmission Electron Microscopy}

By Robert D. Hoidonroich. (Interscience Monographs and Texts in Physics and Astronomy, Vol. 13.) Pp. xiv +414. (New York and London: Interscionce Publishers, a Division of John Wiley and Sons, Inc., 1964.) $109 s$.

T in its first twenty yoars the electron microscope was largely devoted to biological applications, the past decado undoubtedly belongs to metallurgy and metal physics. Beginning with the first successful attempts to prepare samples from bulk aluminium sufficiently thin for imaging in transmission, methods of chemical and olectrolytic otching have been devised for the similar preparation of almost all metals, alloys and more recently serniconductors also. It is in this context that the title of Dr. Heidenreich's book has to be read.

Although in his preface Dr. Heidenreich states tho intention of providing a trcatment of image formation which will be applicable to biological as woll as metal spocimens, in effoct this stops at the atomic level so far as amorphous structures are concerned. Halfa-dozen pages are given to the imaging of moleculos and elementary fibres, but larger biological units are not considered and there is no mention of the work of Lipport, Bahr, Zeitler and others on the problem of determining mass-thicknoss from image contrast in eloctron micrographs.

What tho book does do, and does very well, is to set out the physical bases of electron scattoring and diffraction processes, and then to apply them first to the imaging of porfoct crystals and afterwards to that of actual motals, taking into account grain structure and lattice defects. Four chapters are devoted to the scattering and energy loss of electrons, four to interference and diffraction phenomena, three to diseussion of the origins of contrast in electron microscopical images, and a short final chapter to the rather unrelated topic of electron probo microanalysis. The wavo approach is usod from an early stage, and is developed in great detail. Dr. Heidenreich sticks to his declared intention of dealing with 'fundamentals' and gives no space to tho principles or the operation of electron microscopes, or even to the techniquos for proparing thin specimons.

Within these limits ho provides a most valuable guide to the interpretation of electron micrographs of lattice structures. Tho mathematical treatment is thorough and clearly presented. If the micrographs are not always well onough reproduced to bring out relevant details, the diagrams aro unusually woll drawn, especially those depicting three-dimensional phenomona. On the whole, the author achieves his aim of developing "a cohorent, physical approach to tho understanding of contrast in electron microscope imngos". Its chief shortcoming is the absence of any detailed account of the anomalous absorption theory of electron transmission in crystals. Dr. Heidenreich rocognizes its oxistenee but dismisses it, apparently because there is as yot no clear physical picturo of some of its concepts. This is largely true, and for this roason the thoory would not fit neatly into the development of contrast effects from findamontal interactions. But it has been very successful in describing a number of obsorved phonomona in electron images, and it would not be unusual for an empirical thoory to turn out to bo correct, perhaps on grounds not obvious to its original authors.

To do him justice, Dr. ITeidenreich does give references to papers in which the anomalons absorption theory is sot out, so that roadors can study it and form their own. opinions. Perhaps it is asking too much of an author to give much space to a treatment in which ho does not himsolf boliove. Apart from this omission the book is notable for an exemplary breadth of concoption and clarity of exposition. It is likely to find as much use in courses of advanced instruction as in the research laboratory.

V. F. Cosslett

\section{ELECTROMAGNETIC PHENOMENA}

Natural Electromagnetic Phenomena Below $30 \mathrm{kc} / \mathrm{s}$

Edited by D. F. Bleil. (Proceodings of a NATO Advanced Study Institute held in Bad Homburg, Germany, July 22-August 2, 1963.) Pp. vii +470 . (New York: Plenum Press, 1964.) 17.50 dollars.

7 HIS volume contains the written versions of lectures delivered at a NATO Advanced Study Institute held during July-August 1963. Roaders who are becoming confused by the ever-increasing flow of publications which follow 'conforences', 'courses' or 'study groups' will first wish to know what this volume contains which could not have been published in the normal seientifie journals. To thom it can be said that about one-quarter consists of valuable review articles on subjects where good reviews are needed, and scarce, and that much of the remaining matorial might have been published in the normal way, with moro profit to the readers and to the writers, if not to the publishers.

Throo review articles are particularly appropriate to the title. Lokken writos on "Instrumentation for Receiving Electromagnetic Noise bolow 3,000 c.p.s." and gives an excellent account of the techniques and difficulties of measuring fluctuations of the geomagnetic field in the range of frequencies from $0.001 \mathrm{sec}^{-1}$ to $10^{4} \mathrm{sec}^{-1}$. He dividos the techniques into those useful in the micropulsation band with froquencies less than $5 \mathrm{sec}^{-3}$, in the low E.L.F. or Schumann band betwoon 2 and $50 \mathrm{sec}^{-1}$, and in the band above about $50 \mathrm{sec}^{-1}$. Magnetometers described include those which make use of proton precession and optical pumping, and those which use the flux gate principle. Galejs, writing on "Terrestrial ExtremelyLow-Frequency Propagation", gives a fairly detailed account of the theory of the propagation of waves in the Earth-ionosphere cavity and compares the results with those from experiments. Gallet gives a theoretical account of the production of those V.L.F. emissions which do not arise from lightning flashes. He first outlines some of the simple theoretical idcas which might account for the omission of these radiations through the interaction of incident beams of eloctrons with electromagnetic wavos in the ionospheric or magnetospheric plasma. He then shows how this theory can be extended to include some of his more recent ideas.

Of the other reviow type articles the one by Axford on the nature of the magnetosphere and tho one by Sugiura on "Geomagnotic Storms" will probably be found most interesting. It is a little difficult to see why they should appear in a book with the present title, and it is perhaps unfortunato that they have not been published somewhere else where they will be more widely read.

Other roviows, by MeNish on the aurora and by Gibbons on the ionosphore, seem unduly restricted. In spite of the title, McNish writes mainly about geomagnetism and Gibbons about the propagation of radio waves in the ionosphere, but he restricts his treatment to ray methods, and to frequencies greater than $150 \mathrm{kc} / \mathrm{s}$, which seem to havo little relevance to the present volume.

Most of the romaining papers, not of the review type, could have been published in tho normal way. There are exporimental papers on natural emissions at high latitudes in the frequency range 500-1,000 $\mathrm{sec}^{-1}$ and on observations of ruicropulsations, including somo at conjugate points. Alfvén and his collaborators discuss thoir recent suggestions that the usual magnetospheric model needs essential modification. There are interesting papers on geomagnetic offects caused by high-altitude nuclear explosions 